\title{
Prenatal programming of postnatal development in the pig
}

\author{
G.R. Foxcroft', W.T. Dixon', M.K. Dyck', S. Novak', J.C.S. Harding' \\ and F.C.R.L. Almeida ${ }^{3}$
}

'Swine Reproduction-Development Program, Department of Agricultural, Food and Nutritional Science, University of Alberta, Edmonton, Alberta, T6C 2P5, Canada; ${ }^{2}$ Department of Large Animal Clinical Sciences, 52 Campus Drive, University of Saskatchewan, Saskatoon, Saskatchewan, S7N 5B4, Canada; ${ }^{2}$ Laboratory of Structural Biology and Reproduction, Department of Morphology, Federal

University of Minas Gerais, Belo Horizonte, MG, Brazil

Studies of low birth weight offspring have a long history in pig science. These pigs have reduced growth potential and poor carcass quality compared to their higher birth weight littermates. In contemporary commercial sows with between 10 and 15 total pigs born/litter, between-litter differences in average birth weight appear to make the largest contribution to variation in postnatal growth performance, independent of numbers born. Low birth weight is a characteristic of a subpopulation of these sows, likely as a consequence of an imbalance between ovulation rate and uterine capacity due to ongoing selection for litter size. Based on experimental studies, we hypothesize that increased crowding at day 30 of gestation primarily affects placental development and persistent negative impacts on placental growth then affect fetal development. However, embryonic myogenic gene expression is already affected at day 30 . Latent effects of metabolic state on oocyte quality and early embryonic development have also been reported. In contrast to effects of uterine crowding, the embryo is primarily affected by previous catabolism. The large body of literature on gene imprinting, and the interactions between metabolism, nutrition, and methylation state, suggest that classic imprinting mechanisms may be involved. However, the potential use of genomics, epigenomics, nutrigenomics, and proteomics to investigate these mechanisms brings new demands on experimental design and data management that present a considerable challenge to the effectiveness of future research on prenatal programming in the pig.

\section{Introduction}

Studies of extremely low birth weight or runt pigs have a long history in pig science. Runt pigs ( $<0.8 \mathrm{~kg}$ of birth weight, bw) can be identified as lying outside developmental norms for gestational age at a very early stage of pregnancy. They have a low chance of survival to weaning and of generating viable economic returns to producers. In a review of studies of within-litter variation in prenatal development (Adams 1971, Widdowson 1971, Hegarty \& Allen 1978, Flecknell et al. 1981), Wootton et al. (1983) suggested that the extremes of intrauterine growth restriction (IUGR) or "runting" were identified within a discrete subset of 
fetuses. Subsequently, van der Lende \& de Jager (1991) considered the relationship between within-litter differences in prenatal development and postnatal performance and concluded that the lower pre-weaning growth of the runt pigs in the litter was not completely explained by their lower birth weight. They suggested that IUGR, or runting, had a more complex effect on developmental potential and that the phenomenon of IUGR within a litter was associated with specific patterns of embryonic survival (van der Lende et al. 1990). The largest litters in utero were also most likely to include runt fetuses. Furthermore, these data were consistent with the conclusion that within-litter variation in development was already established at the early fetal stage (day 27 to 35) of gestation. More recently, Finch et al. (2002) used statistical criteria to classify pigs within a litter as either IUGR (clearly low birth weight pigs that were also outliers in the fitted distribution of litter weights), or simply small for gestational age (SGA; more than two standard deviations below the litter mean weight but not statistical outliers). In contrast to data from mature sows discussed later in this review, in these Large White $x$ Landrace gilt litters, no relationship was established between litter size and mean litter weight at day 30 or 100 of gestation, or at birth. Another important conclusion was that in these gilt litters, the authors detected both IUGR and SGA littermates at day 30 of gestation when the effects of crowding would be considered as having minimal impacts on embryo size. These data further support the conclusion that variations in within-litter birth weight are established by day 35 of gestation; however, the mechanisms by which this occurs, if not explained by uterine crowding, are not completely understood.

In general, growth performance in the pre-weaning, nursery, and grow-finish stages of production are impaired in low birth weight pigs (Quiniou et al. 2002, Rehfeldt \& Kuhn 2006). Within-litter comparisons of associations between low $(\sim 1.0 \mathrm{~kg})$ and high $(\sim 1.9 \mathrm{~kg})$ birth weight pigs and postnatal development reviewed by Foxcroft et al. (2007a) indicate that low birth weight littermates have reduced growth potential and poor carcass quality, linked to lower muscle fibre numbers at birth. These postnatal effects of birth weight are consistent with earlier studies of fetal muscle development in the pig and effects of nutrient restriction on myogenesis (see Rehfeldt \& Kuhn 2006). Therefore, the low birth weight of the individual pigs within a litter, and within-litter variation in birth weight, are already of considerable economic interest for postnatal performance in pork production systems.

In the remainder of this review, we wish to contrast the incidence of within-litter variation in individual birth weight with even greater variation in average birth weight of pigs between litters. Changing interactions among the component traits determining litter size at term (ovulation rate, embryonic survival to day 30 , and uterine capacity for normal placental and fetal development) need consideration. In hyper-prolific dam-line sows these interactions characteristically result in large numbers of pigs in utero in late gestation, but relatively poor survival through the periparturient period and low birth weight in both live and stillborn pigs. In less prolific commercial dam-lines, selection for increased litter size has still produced inadvertent crowding of embryos in early gestation in some sows, and this phenotype becomes more prevalent as sows mature, resulting in increased between-litter variation in birth weight. By dissecting the component traits contributing to litter outcomes in these different sow populations, it is possible to suggest the underlying physiological mechanisms involved. Finally, litter phenotypic outcomes can be further complicated by imprinting effects of sow metabolic state on early litter development.

These trends in pig litter phenotypes will be discussed in the context of the large body of research which arose from epidemiological studies in human populations that suggested epigenetic mechanisms likely determine prenatal programming of postnatal outcomes. Experimental studies in laboratory rodents and sheep continue to define the mechanisms linking maternal nutritional state to prenatal programming and are of particular relevance to 
the growing number of "nutrigenomic" studies in the gilt and sow. These mechanisms also presumably underlie the indirect effects of limited placental size due to crowding in utero on embryonic and fetal development. Finally, existing knowledge on prenatal programming in the pig will be discussed from two perspectives. Firstly, the possible impact of multi-generational epigenetic effects on boar and sow fertility. Secondly, the demands on experimental design and data management that need to be met in order to realize the full potential of "omic" analyses in future research on prenatal programming in the pig.

\section{Between-litter variation in birth weight and implications for prenatal programming.}

\section{Responses to selection of hyper-prolific dam-line sows}

As reviewed by Boulot et al. (2008), selection for truly hyper-prolific dam-line sows has been associated with litter traits that are causing problems for efficient and sustainable production. Although the total number of pigs born per litter increased from 11.9 in 1996 to 13.8 in 2006 (Gondret et al. 2005, IFIP 2007), total mortality also increased. Overall, $8 \%$ of all pigs were stillborn, accounting for $40 \%$ of total mortality. Also, with pigs born alive averaging 12.7 per litter, pre-weaning mortality was also high $(15 \%)$ and mainly explained by crushing of weak littermates. Although the average number of pigs weaned still shows a positive trend in these hyper-prolific dam-lines, the growth potential and economic competitiveness of these offspring is likely an issue.

Selection for higher total numbers of pigs born is associated with increased within-litter variation in piglet birth and an overall decrease in birth weight (Quiniou et al. 2007: Table 1). The proportion of pigs weighing less than $1.0 \mathrm{~kg}$ increased from 3 to $15 \%$ and the proportion of pigs $>1.4 \mathrm{~kg}$ fell below $50 \%$ in litters of 16 pigs or more. This suggests that in the large litters born to hyper-prolific sows, growth potential of the live-born pigs that survive to weaning will have been seriously compromised by intra-uterine competition, with an increasing number of stillborn pigs and littermates that die in the immediate period after farrowing (Foxcroft et al. 2007a). Ongoing studies of the reproductive characteristics of a similar line of French hyperprolific sows imported into Canada confirm these suggestions. In the higher parity sows in this population, high ovulation rates are associated with substantial crowding of viable conceptuses at day 30 of gestation (JCS Harding, personal communication) and the overall distribution of birth weights shows the same shift to a lower median birth weight, and an increase in variance in litter birth weights, discussed earlier (M Duggan, personal communication).

A better understanding of the characteristics of specific hyper-prolific dam-lines is needed. This information, and an increasing focus on maximizing net revenues per sow, in terms of saleable pork products relative to the input costs per $\mathrm{kg}$ of pork sold, should allow more commercially sustainable dam-lines to be developed. Ultimately, selection of sows with increased uterine capacity offers the best opportunity for increasing the number of pigs born per litter without compromising the post-natal growth performance of these pigs Uohnson et al. 1999, Quinton et al. 2006, Rosendo et al. 2007). Foxcroft et al. (2007a) suggested that selection for litter characteristics also needs to include data from multiparous sows, with litter average birth weight being used in addition to total pigs born live, as a means of identifying the most efficient lifetime production. The complex interactions among the component traits determining litter size and quality were also highlighted in the review of Distl (2007), who commented that in 
Table 1. Effect of litter size on piglet birth weight (bw) variation. (From Boulot et al. 2008)

\begin{tabular}{lccccc}
\hline Litter size (class) & $<9$ to 9 & 10 to 11 & 12 to 13 & 14 to 15 & 16 to $>16$ \\
\hline Mean parity & 2.6 & 2.3 & 2.5 & 2.6 & 3.5 \\
L.itter: ( $\mathrm{n}-$ ) & 161 & 134 & 245 & 334 & 506 \\
$\quad$ No. total born & 7.2 & 10.6 & 12.6 & 14.5 & 17.6 \\
$\quad$ No. born alive & 7.0 & 10.2 & 11.9 & 13.8 & 16.2 \\
$\quad$ No. stillborn & 0.3 & 0.4 & 0.6 & 0.7 & 1.5 \\
Mean bw, kg & $1.89^{\mathrm{a}}$ & $1.67^{\mathrm{b}}$ & $1.57^{\mathrm{c}}$ & $1.47^{\mathrm{d}}$ & $1.38^{\mathrm{e}}$ \\
CVbw, \% & $14.9^{\mathrm{d}}$ & $17.4^{\mathrm{c}}$ & $20.2^{\mathrm{b}}$ & $21.3^{\mathrm{b}}$ & $23.7^{\mathrm{a}}$ \\
Distribution in bw classes, \% & & & & & \\
$<1.0 \mathrm{~kg}$ & $3^{\mathrm{e}}$ & $5^{\mathrm{d}}$ & $8^{\mathrm{c}}$ & $10^{\mathrm{b}}$ & $15^{\mathrm{b}}$ \\
$1-1.4 \mathrm{~kg}$ & $8^{\mathrm{c}}$ & $16^{\mathrm{d}}$ & $21^{\mathrm{c}}$ & $29^{\mathrm{b}}$ & $34^{\mathrm{d}}$ \\
$1.4-1.8 \mathrm{~kg}$ & $27^{\mathrm{c}}$ & $39^{\mathrm{b}}$ & $43^{\mathrm{a}}$ & $43^{\mathrm{a}}$ & $38^{\mathrm{b}}$ \\
$>1.8 \mathrm{~kg}$ & $63^{\mathrm{a}}$ & $40^{\mathrm{b}}$ & $28^{\mathrm{c}}$ & $19^{\mathrm{d}}$ & $13^{\mathrm{b}}$ \\
\hline
\end{tabular}

a,b,c,d,- Within each row, means with no common superscript differ $(P<0.05)$.

genomic studies, candidate gene effects and quantitative trait loci (QTL) are unlikely to be detected unless each of the component traits contributing to litter outcomes is adequately described in specific sow populations. This provides much of the rationale for studies described in the next section, which attempted to describe these phenotypic traits in contemporary commercial sow populations.

\section{Embryonic and placental development are affected by uterine capacity in early gestation}

Characteristics of IUGR would be a predicted outcome when the number of developing conceptuses in utero exceeds functional uterine capacity. Earlier studies indicated that uterine capacity was generally not limiting until after day 30 of gestation, and that effects of moderate crowding of embryos before day 30 could be compensated by increased placental efficiency later in gestation (see reviews of Foxcroft et al. 2007a,b). The dynamic changes in placental development that occur during gestation that might contribute to such compensatory effects are reviewed elsewhere in this volume (Vallet et al. 2009). However, particularly in studies with higher parity contemporary commercial sows, increased placental efficiency does not appear to fully compensate poor placental development earlier in gestation. Even in individual gilts with 20 or more ovulations, and little or no embryonic loss by day 28-30 of gestation, substantial intra-uterine crowding limits placental development (Almeida et al. 2000). Depending on the particular sow population studied, a consistent trend for increased ovulation rates in higher parity sows (Vonnahme et al. 2002, Town et al. 2005, Patterson et al. 2008) may be associated with increased numbers of embryos (Vonnahme et al. 2002, Patterson et al. 2008) and negative effects on placental weight (Vonnahme et al. 2002) at day 30. However, the interactions among ovulation rate and embryonic survival rate on the one hand, and placental and embryonic weight at day 30 , and placental and fetal weight at day 50 on the other, are complex and are affected by parity of the sow (Table 2).

Several conclusions can be drawn from these data: (1) the proportion of sows with $>25$ ovulations increases with parity, (2) the higher ovulation rates in these sows are positively associated with increased numbers of embryos in the uterus at $d 30$, despite a negative effect on the percent of embryos surviving to day $30,(3)$ in turn, the higher number of embryos at day 30 has a negative impact on placental weight at day 30 , which persists to day 50 , and (4) consistent with Town et al. (2004), no immediate effect of increased numbers of embryos on 
embryonic weight at day 30 is present; however, reduced fetal weight at day 50 was evident, resulting in an interaction between parity, ovulation rate, and gestational age (Table 2). Thus, even within the productive lifetime of commercial sows, the changing dynamics of prenatal loss have important implications for placental and fetal development. Furthermore it is evident that the number of embryos present at day 30 of gestation in commercial sows exceeds normal uterine capacity, limiting embryonic and placental development (Foxcroft \& Town 2004).

Table 2. Interactions among parity grouping, ovulation rate and either numbers of embryos, embryonic survival, and embryonic and placental weight at day 30, or numbers of fetuses, fetal survival, and fetal and placental weight at day 50, in commercial dam-line sows. (Extended data from the study of Patterson ef al. (2008)

\begin{tabular}{|c|c|c|c|c|c|c|c|}
\hline Parity & $\begin{array}{l}\text { Gestation } \\
\text { Day }\end{array}$ & $\begin{array}{c}\text { Ovulation } \\
\text { Rate Class } \\
(n-)\end{array}$ & $\begin{array}{c}\text { Mean } \\
\text { Ovulation } \\
\text { Rate }\end{array}$ & $\begin{array}{c}\text { Nos. Live } \\
\text { Embryos/ } \\
\text { Fetuses }\end{array}$ & $\begin{array}{c}\text { Embryonic } \\
\text { or Fetal } \\
\text { Survival }(\%)\end{array}$ & $\begin{array}{c}\text { Embryonic } \\
\text { or Fetal } \\
\text { Weight (g) }\end{array}$ & $\begin{array}{l}\text { Placental } \\
\text { Weight (g) }\end{array}$ \\
\hline \multirow[t]{4}{*}{ P2-3 } & 30 & $\begin{array}{c}<25 \\
(n-121)\end{array}$ & $20.6 \pm 0.2$ & $\overline{14.9 \pm 0.6}$ & 71.1 & $1.2 \pm 0.8$ & $16.0 \pm 2.0$ \\
\hline & & $\geq 25(n-25)$ & $26.4 \pm 0.5$ & $15.7 \pm 0.6$ & 60.6 & $1.1 \pm 1.5$ & $14.5 \pm 5.5$ \\
\hline & 50 & $\begin{array}{c}<25 \\
(n=119)\end{array}$ & $20.3 \pm 0.2$ & $12.9 \pm 0.6$ & 62.7 & $38.7 \pm 0.8$ & $120.8 \pm 2.0$ \\
\hline & & $\geq 25(n-26)$ & $27.2 \pm 0.5$ & $13.2 \pm 0.6$ & 48.6 & $45.8 \pm 1.6$ & $113.6 \pm 4.3$ \\
\hline \multirow[t]{4}{*}{ P4-6 } & 30 & $<25(n-28)$ & $21.5 \pm 0.5$ & $15.8 \pm 1.0$ & 70.0 & $1.4 \pm 1.7$ & $16.7 \pm 4.2$ \\
\hline & & $\geq 25(n-21)$ & $26.8 \pm 0.5$ & $17.3 \pm 1.0$ & 66.2 & $1.4 \pm 1.7$ & $15.9 \pm 4.8$ \\
\hline & 50 & $<25(n-26)$ & $21.2 \pm 0.5$ & $10.8 \pm 1.1$ & 50.9 & $52.1 \pm 1.8$ & $121.8 \pm 4.4$ \\
\hline & & $\geq 25(n-22)$ & $27.6 \pm 0.5$ & $10.6 \pm 1.0$ & 38.6 & $46.5 \pm 1.6$ & $104.9 \pm 4.7$ \\
\hline \multirow[t]{7}{*}{ P7+ } & 30 & $<25(n-17)$ & $21.8 \pm 0.6$ & $12.6 \pm 1.2$ & 60.3 & $1.5 \pm 2.5$ & $18.9 \pm 5.3$ \\
\hline & & $\geq 25(n-18)$ & $26.3 \pm 0.6$ & $14.8 \pm 1.2$ & 55.2 & $1.4 \pm 2.3$ & $15.4 \pm 5.3$ \\
\hline & 50 & $<25(n-31)$ & $21.8 \pm 0.4$ & $12.4 \pm 1.1$ & 57.4 & $54.4 \pm 2.0$ & $107.1 \pm 3.9$ \\
\hline & & $\geq 25(n-19)$ & $28.4 \pm 0.6$ & $10.7 \pm 1.5$ & 38.6 & $50.4 \pm 3.1$ & $102.0 \pm 3.9$ \\
\hline & & Parity $(P)$ & 0.07 & NS & 0.07 & $<0.001$ & NS \\
\hline & & Gestation (G) & $<0.001$ & $<0.001$ & $<0.001$ & $<0.001$ & $<0.001$ \\
\hline & & $P^{*} G$ & 0.06 & $<0.05$ & 0.06 & $<0.001$ & $<0.06$ \\
\hline \multirow[t]{4}{*}{$P$-Value } & Ovulat & ion Group (O) & $<0.001$ & NS & $<0.001$ & NS & $<0.05$ \\
\hline & & $\mathrm{P} * \mathrm{O}$ & NS & NS & NS & $<0.01$ & NS \\
\hline & & $\mathrm{G}^{*} \mathrm{O}$ & NS & 0.09 & NS & NS & NS \\
\hline & & $\mathrm{P} * \mathrm{C} * \mathrm{O}$ & NS & NS & NS & $<0.01$ & NS \\
\hline
\end{tabular}

Experimental approaches to the study of prenatal programming of litter development.

An initial experiment with weaned third parity sows indicated that although an increasing number of viable embryos determined by laparotomy at day 30 did not affect average litter birth weight, characteristic impacts of IUGR were evident in neonates necropsied at term (Town 2004). In a second experiment, unilateral oviduct ligation in the weaned sow was used to effectively reduce the number of embryos and fetuses developing in the uterus compared to the relatively crowded intra-uterine environment of control sows (Town et al. 2004). Even though the difference in uterine crowding achieved did not replicate the extremes of intra-uterine crowding discussed above in commercial sows, the higher number of embryos at day 30 limited placental but not embryonic weight at that stage, and negatively affected both placental and fetal weight at day 90 . Among the various measures of IUGR recorded, there were specific effects on the brain:muscle weight ratio, brain to muscle fibre number ratio, estimated total number of secondary muscle fibres, and associated differences in the wet weight and cross sectional area of the semitendinosus muscle (Table 3). Further analyses determined that even at day 
30, down-regulation of myogenin expression was present in the relatively crowded embryos (Tse et al. 2008). This provided some of the first evidence that functional uterine capacity for optimal placental development at day 30 is below the threshold for embryonic survival per se at this stage of gestation reviewed elsewhere (Foxcroft et al., 2007a). The data confirm our hypothesis that increasing the number of conceptuses surviving to the post-implantation period initially limits placental development at day 30 , and as a consequence, then limits placental function later in gestation and produces fetuses at day 90 that already show characteristics of IUGR. The recorded effects of inadvertent intra-uterine crowding in early gestation on expression of myogenic regulatory genes would also contribute to differences in fetal muscle fibre development, birth weight, and post-natal growth performance in affected litters.

As discussed later, the effects of prenatal programming on postnatal performance are not limited to effects on muscle development and growth. Epidemiological studies in human infants led to the "Barker hypothesis", linking pre-natal programming of the fetus to lifetime health outcomes (see Barker 1994). Harding et al. (2006a,b) discussed similar associations in the pig in the context of development of the immune system and early postnatal survival. In a preliminary analysis of brain sparing effects, it was demonstrated that the organs most notably affected in stillborn pigs with low relative birth weights compared to their littermates were the heart, liver, and spleen. These and other developmental complications, undoubtedly underlie the problems of managing low birth weight pigs through the lactation and nursery stages of production. In ongoing studies in mature commercial sows, the unilateral oviduct occlusion technique is being used by the same group to explore the impact of differences in intra-uterine crowding early in gestation on development of immune competence at birth.

A second approach to determine the origins of increased between-litter variation in litter average birth weight was the retrospective analysis of available litter phenotypic data from large breeding nucleus populations (Smit 2007) and the collection of individual litter data in a study of $\mathrm{L}$-arginine supplementation to the gestation diet of commercial sows from the same population used by Patterson et al. (2008). Litter average birth weight and between-litter variance in litter average birth weight were both consistently lower in the largest litters ( $>15$ total born) in these populations (Fig. 1), analogous to the situation in hyper-prolific sows discussed earlier. This suggests that the birth weight of most pigs born in litters $>15$ is relatively low because the threshold of uterine capacity for supporting pigs within the upper percentiles of birth weight $(1.6$ to over $2.0 \mathrm{~kg}$ ) is around 15 fetuses. At the other extreme, in litters of $<10$ pigs, low litter average birth weight should not be due to limited uterine capacity, unless high ovulation rates combined with high peri-implantation embryonic survival resulted in very serious limitations in placental development.

As is evident in Fig 1, in the population of litters with between 10 and 15 total pigs born, large variation in litter average birth weight existed, independent of litter size. Smit (2007) compared the characteristics of low and high average birth weight litters within this same subpopulation, having defined high and low average birth weights as being more or less than $0.2 \mathrm{~kg}$ relative to the average litter birth weight for the whole population (approximately $1.4 \mathrm{~kg}$ ). The resulting dataset included 1,094 litter records representing the top 15\% (High) and bottom $15 \%$ (Low) of the population in terms of litter average birth weight (Table 3). In litters with a Low average birth weight, fewer pigs were born alive, more pigs were born dead, and fewer pigs survived to weaning, consistent with the hypothesis that these litters had been subjected to negative effects of IUGR. Furthermore, these litters exhibit lower within litter variation in birth weight possibly resulting from the prenatal loss of the smaller fetuses in a crowded intra-uterine environment. In contrast, in High average birth weight litters not subjected to extremes of intra-uterine crowding, pigs across a wider range of birth weights have the opportunity to survive to term. 


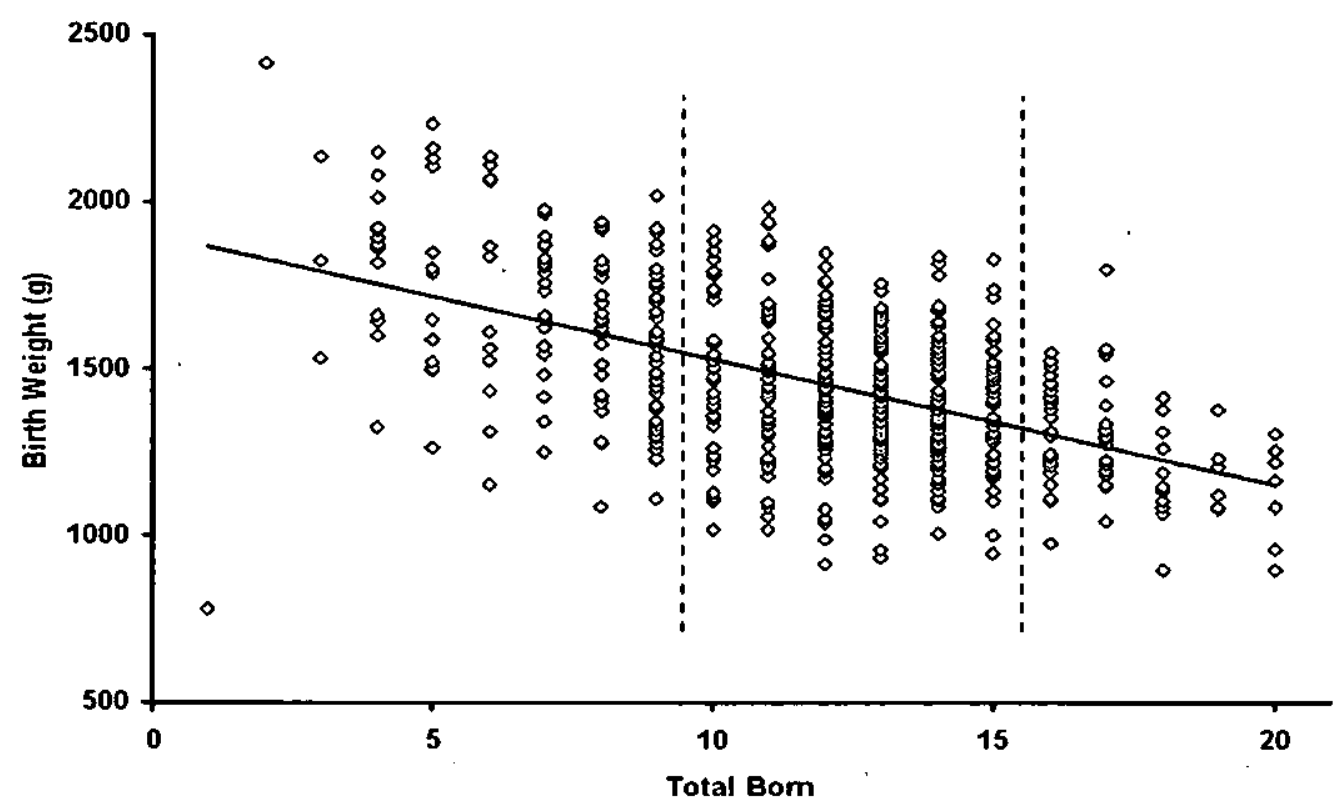

Fig. 1 Negative correlation between litter average birth weight and total born in all litters, grouped by litter sizes of less than 10,10-15, and greater than 15, using total born as a covariate $\left(n=580 ; r^{2}=-0.28 ; P \leq 0.001\right)$. (University of Alberta, unpublished data, 2007)

Table 3. Characteristics of litters classified as having a higher than average (High) and lower than average (Low) birth weight (bw), and in litter sizes of between 10 and 15 total pigs born (After Smit 2007).

\begin{tabular}{lccc}
\hline & High & Low & P-Value \\
\hline Average birth weight $(\mathrm{kg})$ & $1.8 \pm 0.01$ & $1.2 \pm 0.01$ & $<0.001$ \\
Standard deviation in bw & 0.287 & 0.272 & 0.01 \\
Total born & $12.3 \pm 0.08$ & $12.3 \pm 0.07$ & $\mathrm{NS}$ \\
Born alive & $11.7 \pm 0.09$ & $11.0 \pm 0.09$ & $<0.001$ \\
Born dead & $0.6 \pm 0.07$ & $1.2 \pm 0.06$ & $<0.001$ \\
Weaned & $10.8 \pm 0.10$ & $9.4 \pm 0.10$ & $<0.001$ \\
\hline
\end{tabular}

The concept that low average birth weight is associated with characteristic effects of IUGR, and could be linked to effects of intra-uterine crowding on placental development in litters of between 10 and 15 pigs total born, was further explored by performing necropsies on any still-born pigs born in a proportion of the litters represented in Fig 1 and by estimating average placental wet weight immediately after farrowing in these litters (Fig 2a). Relevant to this review, necropsy was only performed if pigs were truly still-born (confirmed by lung floatation tests) and their weights fell within the mid-weight range of their respective live-born littermates. The inverse relationship between litter average birth weight and wet placental weight (Fig 2a), and between litter average birth weight and organ weights ( $F i g 2$ b), support the conclusion that low birth weight litters show characteristics of IUGR and that this may be functionally linked to limited placental development. Based on the prevalence of high ovulation rates, and an average of 15.7 and 17.3 embryos at day 30 in the parity $2-3$ and $4-6$ sows reported by Patterson et 
al. (2008), these data are considered to support the principal hypothesis driving our ongoing research "that changing dynamics of pre-natal loss of embryos in contemporary commercial sow populations limits placental development and indirectly causes IUGR" and that in this situation "IUGR is a characteristic of entire low birth weight litters" (Foxcroft et al. 2007a).

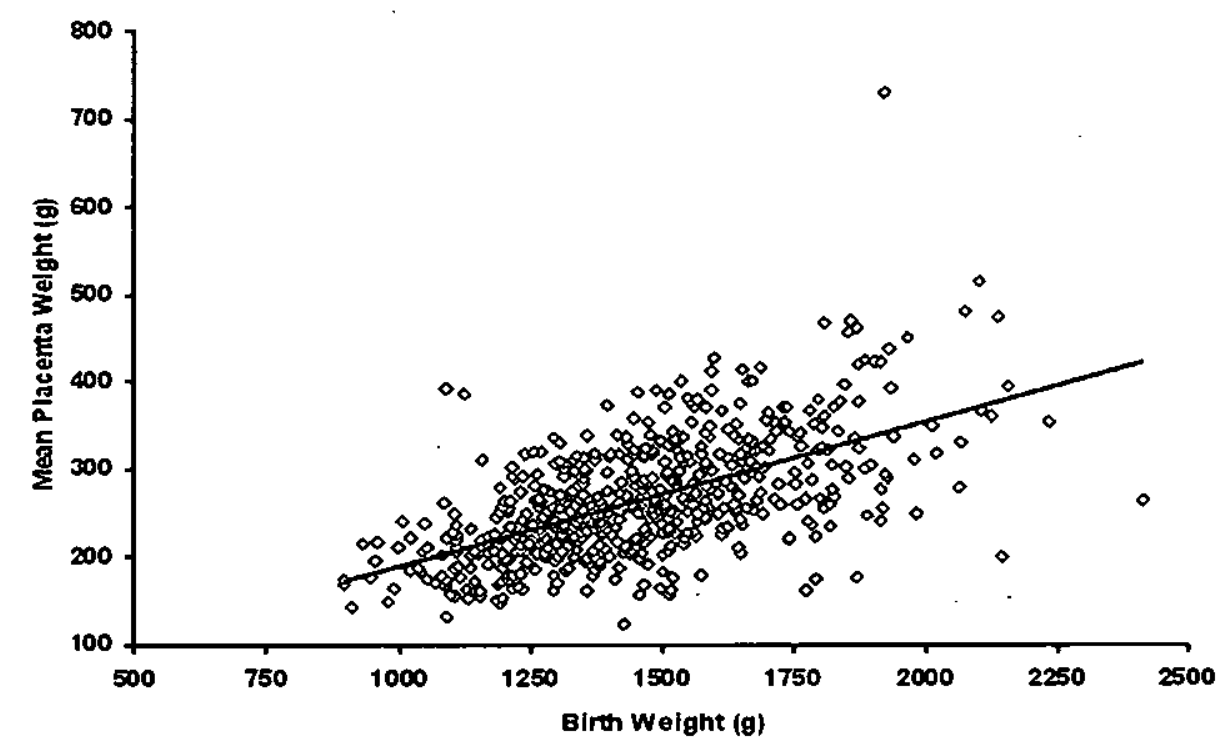

Fig. 2a Correlation between average placental wet weight and litter average birth weight (bw) for each litter $\left(n=586: r^{2}=0.41: P<0.001\right)$

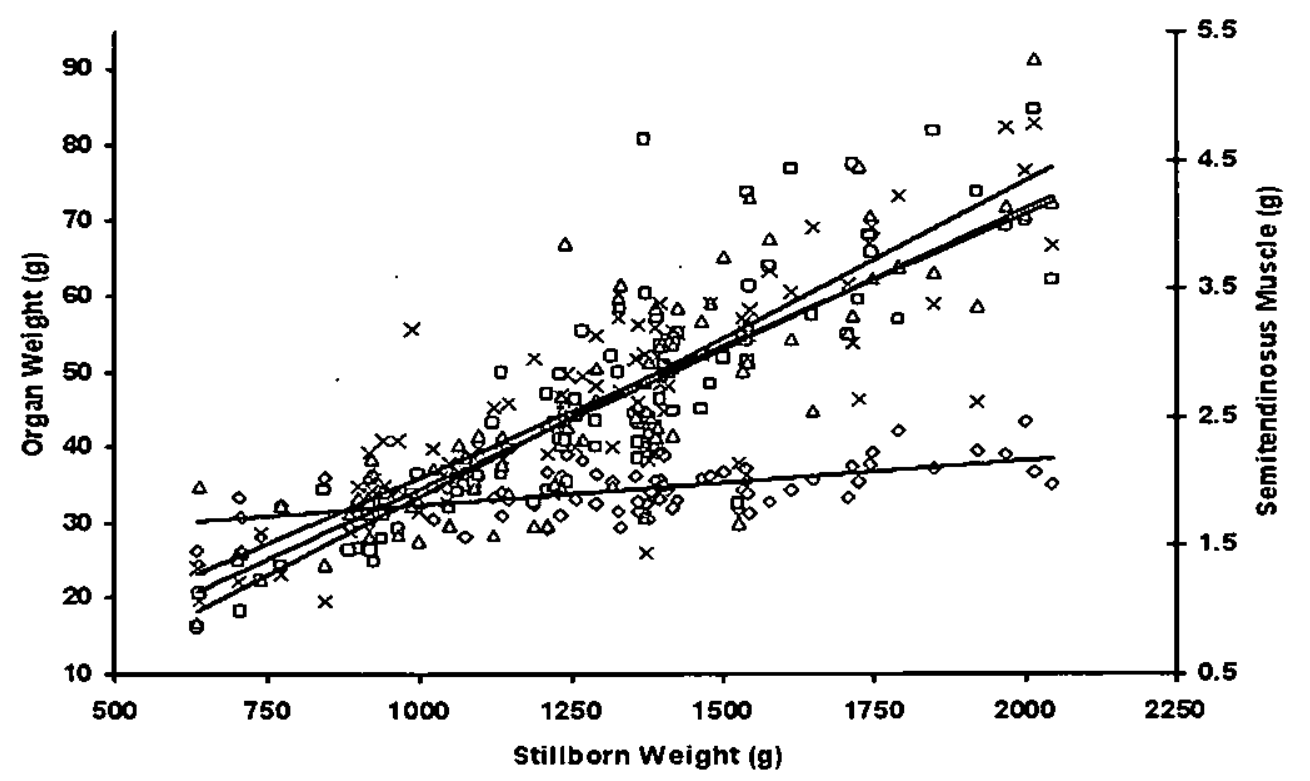

Fig. $2 b$ Fitted linear relationships between weight of the brain (diamonds; $y=0.0059 x$ $+26.436 ; r^{2}=0.35 ; P<0.001$ ), small intestine (squares; $y=0.0417 x-8.2041 ; r^{2}=$ $0.76 ; P<0.001$ ), liver (triangles; $y=0.0371 x-2.6725 ; r^{2}=0.69 ; P<0.001$ ), and semitendinosus muscle (crosses; $y=0.002 x-0.0236 ; r^{2}=0.71 ; P<0.001$ ) in relation to the weight of stillborn pigs $(n=87$ ). (University of Alberta, unpublished data, 2007) 


\section{Latent effects of metabolic state on prenatal development}

The nutritional and metabolic state of the gilt or sow can exert direct and classic epigenetic effects on embryonic development, representing an alternative source of prenatal programming of whole litters due to environmental effects on the oocyte and developing embryo (see Foxcroft et al. 2006, 2007b). A deficit in nutrient availability at any stage of gestation may also trigger changes in litter development and Wu et al. (2006) reviewed evidence for the link between nutrient availability and IUGR in domestic livestock species. The extent to which nutrient restriction leads to limited, but normal, development, or results in more profound reprogramming of the developmental process (associated with characteristics of IUGR), will depend on the nature and severity of the restriction, the sensitivity of each litter to such nutrient challenges, and the window of development over which the restriction occurs. As an example, nutrient restriction due to limited placental development before day 30 may permanently reprogram myogenesis, with lasting consequences for growth potential and carcass quality (see Foxcroft et al. 2006). Alternatively, nutritional changes after myogenesis is complete may still affect birth weight but may not irreversibly change post-natal growth potential.

Results from an ongoing series of experiments using nutritional restriction of the sow in late lactation to understand the mechanisms mediating effects of catabolism on subsequent fertility have been reviewed previously (Foxcroft et al. 2007b). Selection for increased prolificacy and fertility appears to have changed the nature of the response to a catabolic state in late lactation. An extended weaning-to-estrus interval is no longer a typical response, and ovulation rate, fertilization rate, and embryonic survival to the expanded blastocyst stage are also not affected. Decreased embryonic survival to day 30 may be present but seems to affect a specific subpopulation of litters (Vinsky et al. 2006), again indicating the variable sensitivity of particular sows to similar catabolic (environmental) challenges. It is still uncertain whether loss of embryos is associated with increased heterogeneity in early embryonic development within affected litters, but the loss of embryos may be gender specific (Vinsky et al. 2006, 2007b). The most consistent response to a previous catabolic state is a reduction in embryonic weight, which is usually independent of any comparable effect on placental development and is not genderspecific (Table 4).

Table 4. Least square means \pm SEM for sow reproductive performance, embryonic survival and embryonic and placental weight at day 30 of gestation, in primiparous Control sows $(n=16)$ and sows feed-Restricted ( $n=17)$ during the last week of a 21-day lactation (After Vinsky et al. 2006)

\begin{tabular}{lcc}
\hline Item & Control & Restricted \\
\hline Wean-to-estrous interval (days) & $5.3 \pm 0.3$ & $5.4 \pm 0.3$ \\
Ovulation rate (Number of CL at day 30) & $18.3 \pm 0.7$ & $18.2 \pm 0.6$ \\
Day of gestation at slaughter & $30.3 \pm 0.2$ & $30.1 \pm 0.2$ \\
Embryonic survival (\%) to day 30* & $79.2 \pm 4.0$ & $67.9 \pm 3.9$ \\
Number of surviving male embryos & $7.7 \pm 0.6$ & $7.5 \pm 0.6$ \\
Number of surviving female embryos* & $\mathbf{6 . 5} \pm \mathbf{0 . 6}$ & $\mathbf{4 . 7} \pm \mathbf{0 . 6}$ \\
Embryo weight (g) ** & $\mathbf{1 . 5 3 \pm 0 . 0 7}$ & $\mathbf{1 . 3 8} \pm \mathbf{0 . 0 7}$ \\
Placental weight (g) & $22.6 \pm 1.9$ & $22.8 \pm 1.9$ \\
\hline
\end{tabular}

$* P<0.05, * * P<0.01$ compared to Control sows

In earlier studies using oocyte in vitro maturation (IVM) assays, a lower proportion of oocytes recovered from previously catabolic sows reached the metaphase II stage of nuclear maturation and follicular fluid recovered from preovulatory follicles of these sows was less able to support IVM of pools of oocytes recovered from prepubertal gilts (Zak et al. 1997). These results 
were supported by later studies linking the degree of protein catabolism in weaned sows to a decrease in the size, number and maturity of follicles at the time of weaning, and again, the ability of follicular fluid aspirated from these follicles to support IVM of standardized pools of pig oocytes (Yang et al. 2000, Clowes et al. 2003). As the timing of feed restriction coincides with the final stages of oocyte maturation and the establishment of methylation-dependent imprinting of the oocyte (Lucifero et al. 2002, see detailed discussion below), imprinting of oocytes may be one mechanism by which catabolism in the sow affects embryonic survival and development by day 30 . Consistent with this suggestion, Vinsky et al. (2007a) reported that reduced embryo development and decreased female embryo survival in litters of previously feed restricted sows were associated with differences in the variance of epigenetic traits in the surviving litters at day 30 . As variance in Igf $2 r$ expression tended to decrease $(P<0.07)$ in female embryos in these sows, whilst variance in Xist expression tended to decrease in male embryos $(P<0.08)$, these authors suggested that maternally inherited epigenetic defects may cause female embryonic loss and reduced growth in all surviving embryos by day 30 of gestation. However, no changes in global methylation of blastocyst DNA, and no differences in litter sex ratios or embryonic development were evident when blastocysts were studied at day 6 of gestation (Vinsky et al. 2007b). Collectively, these studies suggested that a subset of litters within restrict-fed sows will be most sensitive to the latent epigenetic mechanisms that ultimately trigger loss of embryos by day 30 of gestation, but that these selective mechanisms were not evident by day 6 of gestation. A number of theories linking gender-specific loss of embryos to differences in the rate of embryonic development and species-specific survival strategies were also reviewed by Foxcroft et al. (2007a), but evidence supporting such theories in the pig are generally lacking.

Detailed analysis of the transcriptome and epigenome of the maturing oocyte and preovulatory follicle will be an important step in defining pre-ovulatory mechanisms that program subsequent embryonic development. Studies of the complex intra-follicular signalling pathways that regulate oocyte maturation in the pig are reviewed by Hunter \& Paradis in this volume (Hunter and Paradis 2009). As yet there is no evidence for major changes in these regulatory pathways that would explain differences in oocyte competence in weaned, catabolic sows, compared to sows bred in an anabolic state at their second post-weaning oestrus (Paradis et al. 2009). However, using the same experimental paradigm as Vinsky et al. (2006), we have preliminary evidence suggesting that differences in embryonic development may be linked to differences in luteal weight early in gestation (Novak S, personal communication). As discussed previously (Foxcroft et al. 2000), this raises the possibility that steroid-dependent modifications in the oviductal and uterine environment may be yet another component of the epigenetic mechanisms controlling pre-natal development.

\section{Epigenetic regulation of pre- and post-natal development}

The large body of literature on the interactions between metabolism, nutrition, and methylation state, suggests that similar mechanisms are likely operating in the pig. A review of mechanisms determining prenatal programming of postnatal outcomes based on epidemiological studies in human populations, and experimental studies in laboratory rodents and sheep in particular, suggest avenues for further exploration in swine. The comprehensive review of Reik (2007) on regulation of mammalian development opens with the statement: "Development is, by definition, epigenetic". The complex regulatory pathways that allow somatic cells to change from a pluripotent state and follow very different pathways of differentiation as the embryo and fetus develops are elegantly described in Fig 3 (taken from Reik 2007). Within these 
developmental processes, the requirements for primordial germ cell (PGC) development, and unique methylation processes involved in sperm and oocyte development, are of particular interest. The role of methylation pathways and specific DNA methyltransferases (DNMTs) in these developmental processes was comprehensively reviewed by Kelly \& Trasler (2004), and the role of methylation state and other regulatory processes was further explored by Reik (2007). A process of global demethylation (erasure) in the PGC is followed by a process of de novo methylation (establishment) in the developing gonads. Methylation-dependent imprinting is completed in gonocytes by the peri-natal period and several DNMTs (DNMT1, DNMT3a, DNMT3b, and DNMT1I) are needed to establish and maintain methylation imprints in both the male and female germ cells (see review of Kelly \& Trasler 2004 for details). Methylationdependent imprinting of the oocyte occurs post-natally, as antral follicles emerge from the resting pool and enter the process of follicular development. Methylation is complete by the metaphase II stage of oocyte nuclear maturation, and although an oocyte-specific isomer of DNMT1, DNMT1o, is transcribed, its role seems to be more related to maintaining maternal methylation imprints during early embryonic development, than in the initial establishment of imprinting in the developing oocyte. The maintenance of the methylated state of imprinted genes in the immediate post-fertilization period in mammals seems to be a unique phenomenon and contrasts to the period of global demethylation and then de novo methylation of non-imprinted genes in the period between fertilization and the blastocyst stage of development shown in Fig 3. The DNA methylation mark is stable, heritable and can regulate specific monoallelic gene expression throughout life (Kelly \& Trasler 2004)

The role of DNA methylation and histone modifications in the regulation of monallelic expression of imprinted genes is of particular significance to prenatal programming. For example, maternal expression of $\mathrm{H} 19$ in the female is paralleled by methylation-dependent suppression (silencing) of the paternal H19 as part of the imprinting process, whereas maternally H19 and IGF2, are expressed but IGF2 is silenced. The interaction of these paternally and maternally expressed imprinted genes plays a critical role in determining the pattern of early embryonic development by regulating the biologically active pool of IGFs that regulate early embryonic and placental growth. Although much of the existing information on methylation pathways and gene imprinting has been obtained from studies with laboratory rodents, comparable information on methylation-dependent imprinting of the IGF2-H19 complex in the pig was recently reported by Park et al. (2009).

Because the methylation imprint in the female is established at the time of oocyte maturation, the metabolic state of the gilt or sow during the period of follicular growth preceding ovulation can exert important effects on this methylation process. Subsequently, nutrition and metabolic state can affect methylation processes and hence the global de novo methylation in the early embryonic stages and methylation maintenance in later gestation. The link between nutritional state and methyl donor pathways has been clearly described in the case of folate metabolism as shown in Fig. 4, taken from the review of Kelly \& Trasler (2004). In turn, the mechanistic link between these pathways and extensive literature on folic acid and other nutritional deficiencies in the sow, and adverse effects on embryonic survival and embryonic growth in the pig, are self-evident (see Foxcroft 1997).

Experimental evidence for the importance of specific nutrients as intermediaries in critical methylation pathways comes from studies in protein-restricted rats in which supplementation of the restrict diet with glycine or folic acid reversed the effects of protein restriction on DNMT1 expression and prevented the abnormal phenotype from developing (for detailed references see Burdge et al. 2007). Working from the opposite perspective, in the study of Sinclair et al. $(2007)$ in sheep, restricting the supply of $B$ group vitamins $\left(B_{12}\right.$ and folate) and methionine in 


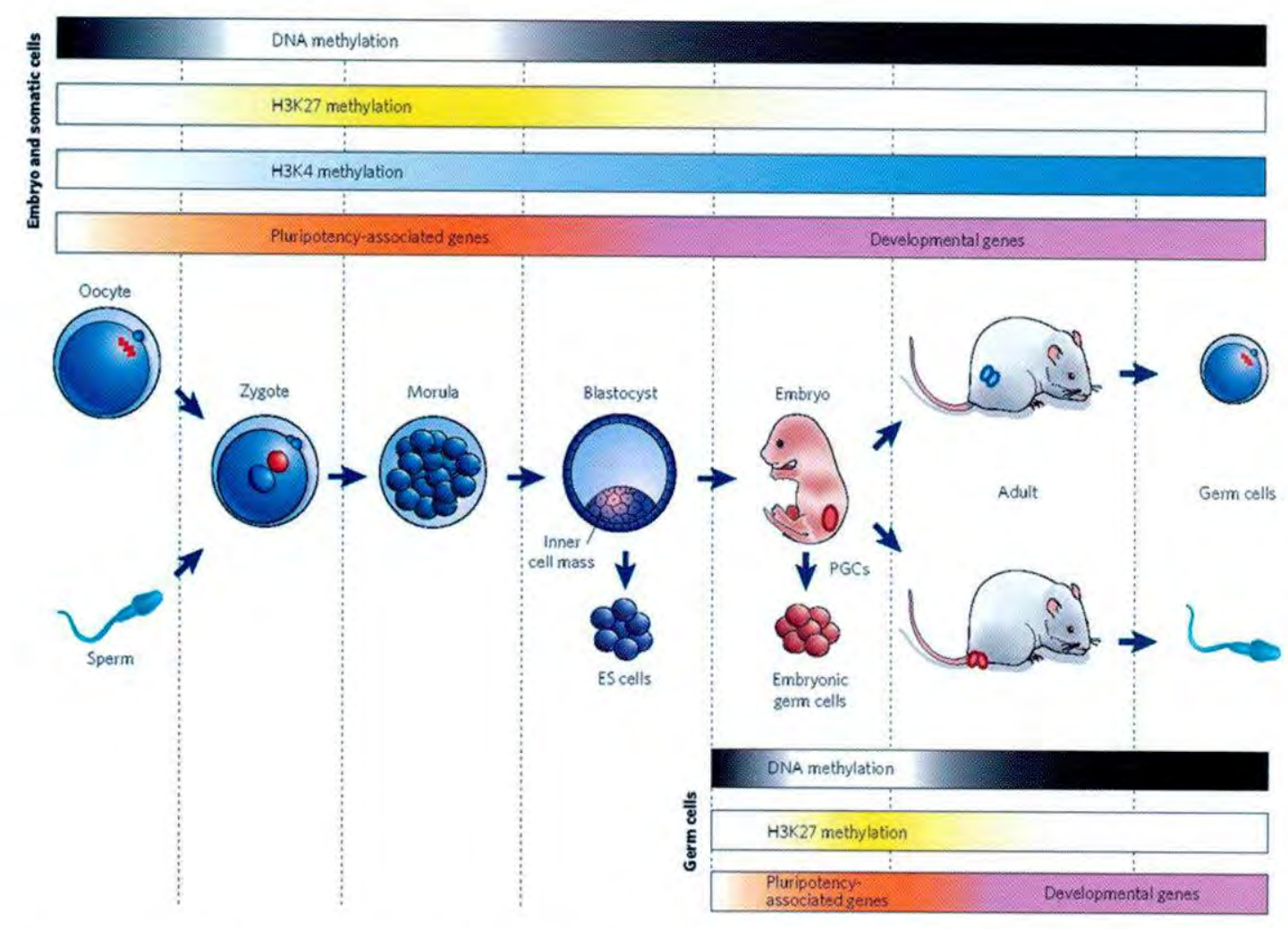

Fig. 3 Epigenetic gene regulation during mammalian development. Key developmental events are shown together with global epigenetic modifications and gene-expression patterns. Very early in development, DNA methylation is erased. In addition, pluripotency-associated genes begin to be expressed, and developmental genes are repressed by the PcG protein system and H3K27 methylation. During the differentiation of pluripotent cells such as ES cells, pluripotency-associated genes are repressed, potentially permanently, as a result of DNA methylation. At the same time, developmental genes begin to be expressed, and there is an increase in $\mathrm{H} 3 \mathrm{~K} 4$ methylation. During the early development of PGCs, DNA methylation and repressive histone modifications (such as $\mathrm{H} 3 \mathrm{~K} 9$ methylation) are also erased. Pluripotency-associated genes are re-expressed during a time window that allows embryonic germ cells to be derived in culture. Imprinted genes are demethylated during this period, and developmental genes are expressed afterwards. Flexible histone marks such as H3K27 methylation enable developmental genes to be silenced for a short time in pluripotent cells. By contrast, DNA methylation enables the stable silencing of imprinted genes, transposons and some pluripotency-associated genes. (from Reik, 2007 with permission) 


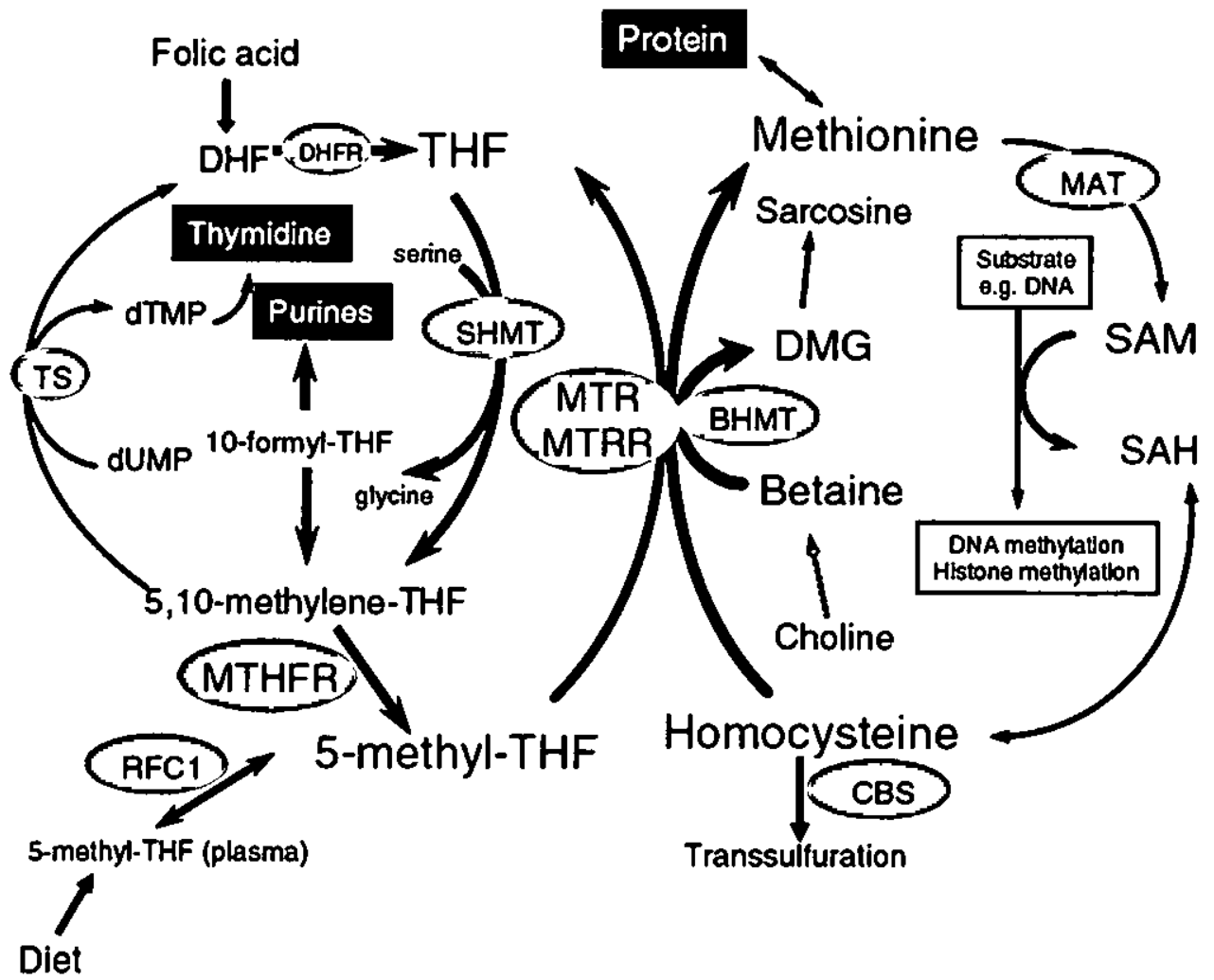

Fig. 4 The folate pathway depicting many of the enzymes involved. This pathway is intrinsic to methylation of both DNA and histones. Disruptions in this cycle can alter production of S-adenosylmethionine (SAM), which is required for methyl donation. BHMT, betaine homocysteine methyltransferase; CBS, cystathionine B-synthase; DHF, dihydrofolate; DHFR, dihydrofolate reductase; DMG, dimethylglycine; MAT, methionine adenosyltransferase; MTHFR, methylenetetrahydrofolate reductase; MTR, methionine synthase; MTRR, methionine synthase reductase; RFC1, reduced folate carrier 1 ; SAH, S-adenosylhomocysteine; SHMT, serine hydroxy methyltransferase; THF, tetrahydrofolate; TS, thymidylate synthase (from Kelly \& Trasler 2004 with permission)

the diet of ewes until shortly after conception led to altered phenotypes in the offspring born to embryos coming from the nutritionally deficient dams and then transferred to normal surrogate mothers as day 6 blastocysts. The authors also reported direct evidence of altered methylation state in adult liver cells of these offspring. These studies clearly indicate the potential to study the role of similar nutrients as mediators of methylation-dependent pathways controlling phenotypic outcomes in the pig. Such nutrients might be used to counteract nutrient deficiencies resulting from limitations in voluntary feed intake in late lactation, when many younger sows enter a catabolic state because the nutritional demands of high milk production are met by mobilization of the sow's fat and protein reserves. Equally, "nutrigenomic" approaches to alleviating problems of nutrient supply to the early embryo created by intra-uterine crowding and limited placental development may be possible. The recent results of Mateo et al. (2007) in the gilt provided evidence of beneficial responses to $L$-arginine supplementation during later gestation on the number of live born pigs. Other preliminary results presented in this volume also indicate that L-arginine supplementation earlier in gestation may affect placental gene expression in mature commercial sows and could 
therefore be beneficial for prenatal development. Gabler et al. (2007) have reported beneficial effects of feeding (n-3) poly-unsaturated fatty acids during gestation and lactation in the pig on intestinal glucose absorption measured in the offspring at weaning and it will be interesting to explore the mechanisms in utero that mediate these effects.

In a more general sense, nutritional manipulations, and particularly protein restriction, have been used to model the outcomes reported in classic epidemiological studies in human populations (Barker 1994). Burdge et al. (2007) emphasize that the concept that "the response of the fetus to nutritional cues from the mother potentially gives rise to a large number of phenotypes from one genotype" as part of a successful survival strategy. Another important concept is that whatever the mechanisms involved, these phenotypes are stable and will produce lifetime changes in the morphology and metabolic activity of the offspring. In many published studies in rodents, the link between protein restriction of the dam in gestation and altered metabolism after birth (insulin resistance, hypertension, etc) involves increased glucocorticoid receptor expression in somatic tissues, decreased expression of genes controlling corticosteroid metabolism, and indirectly an increase in hepatic enzyme activity that promotes gluconeogenesis as a response to predicted protein deficiency in the post-natal environment (see Burdge et al. 2007). The pathway by which protein restriction was thought to interact with glucocorticoid status to induce methylationdependent changes in gene regulation in differentiating tissues is shown in Fig 5. In this model, a failure to maintain methylation at several levels of gene transcription ultimately leads to expression of genes (in this case in the liver) that would not normally be developmentally expressed at this stage of development if nutrition of the dam was normal.

A case for a more universal role for glucocorticoids as being "most likely to cause tissue programming in utero" was presented in the review of Fowden \& Forhead (2004) in the context of more diverse origins of IUGR, including placental insufficiency. The diagrammatic representation of the cascade of hormonal events resulting from a change in nutritional state, and by inference changes that would also be triggered by limited placental development presented in the present review, is shown in Fig 6.

\section{Implications for further research in the pig}

The extensive literature briefly summarized above clearly links varying nutritional state of the dam, and placental competence to deliver nutrients to the developing embryo and fetus, to a wide range of possible birth phenotypes. There is also convincing evidence that the methylation state of imprinted genes that direct prenatal development are sensitive to the nutritional state of the dam and to the manipulation of specific metabolic pathways involved in maintaining methylation-dependent suppression of imprinted genes. Although the epigenetic impact of the gilt or sow "environment" on the birth phenotype of the litter is considered over a relatively short post-natal period in commercial finishing pigs, impacts on muscle development, gut development and nutrient absorption, immune status, and disease susceptibility, will have a major impact on the economic performance of the multiple phenotypes presently produced. A better understanding of the origins of these phenotypes and the extent to which they can be effectively managed will be of benefit to the pig industry. In the longer term, an understanding of the mechanisms that underlie the gene $x$ environmental interactions that result in very different birth phenotypes from dam-line sows with essentially the same genetic merit, will allow better selection strategies to be developed for difficult to measure polygenic traits. Better management of the component traits that determine litter size, and very clearly litter quality, is an excellent example. 


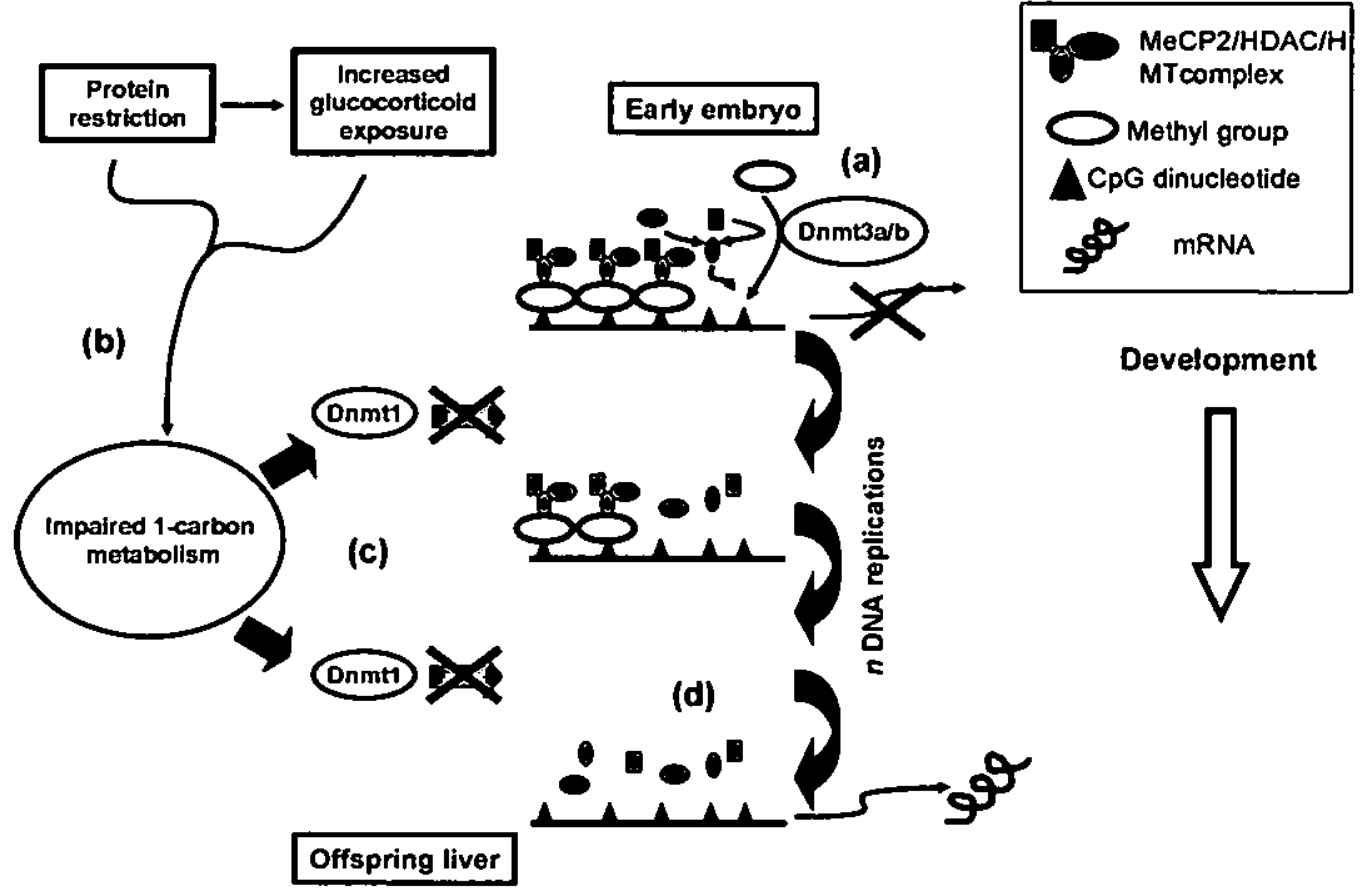

Fig. $5 \mathrm{~A}$ pathway for induction of altered epigenetic regulation of the expression of specific genes in the offspring of rats fed a protein-restricted (PR) diet during pregnancy. (a) Gene expression is silenced in the early embryo by the activities of DNA methyltransferases (Dnmt) $3 a$ and $3 b$. (b) In the offspring of rats fed a PR diet, 1-carbon metabolism is impaired either as a direct consequence of the restricted diet or by increased glucocorticoid exposure. This down-regulates Dnmt 1 expression (c). Lower Dnmt 1 expression results in impaired capacity to methylate hemimethylated DNA during mitosis (d). After sequential mitotic cycles the methylation status of the promoter is reduced and expression is induced in cells which do not express the gene in control animals. Increased gene expression is facilitated by lower binding and expression of methyl $\mathrm{CpG}$ binding protein (MeCP)-2 and reduced recruitment of the histone deacetylase (HDAC) / histone methyltransferase (HMT) complex, resulting in higher levels of histone modifications which permit transcription. (from Burdge et al. 2007 with permission)

\section{Multi-generational effects on fertility}

Evidence for multi-generational carryover effects of induced phenotypes has implications for commercial pig production at the level of genetic multiplication. In theory, prenatal programming of undesirable litter phenotypes in the litters derived from gilts or sows at the multiplication level will impact the lifetime performance of the boars and gilts selected as breeding herd replacements. Such "environmental" effects of the litter of origin are very obvious in studies on the reproductive physiology of the gilt and sow, and the "litter effect" is usually controlled in better designed studies. At production level, the most rigorous selection programs for replacement gilts take account of the possible negative impact of low birth weight on lifetime performance. In many ways, this selection against low birth weight may seem counter-intuitive, because low birth weight offspring may come from the largest litters in terms of number born, and selection for increased prolificacy has been a major part of dam-line selection programs 


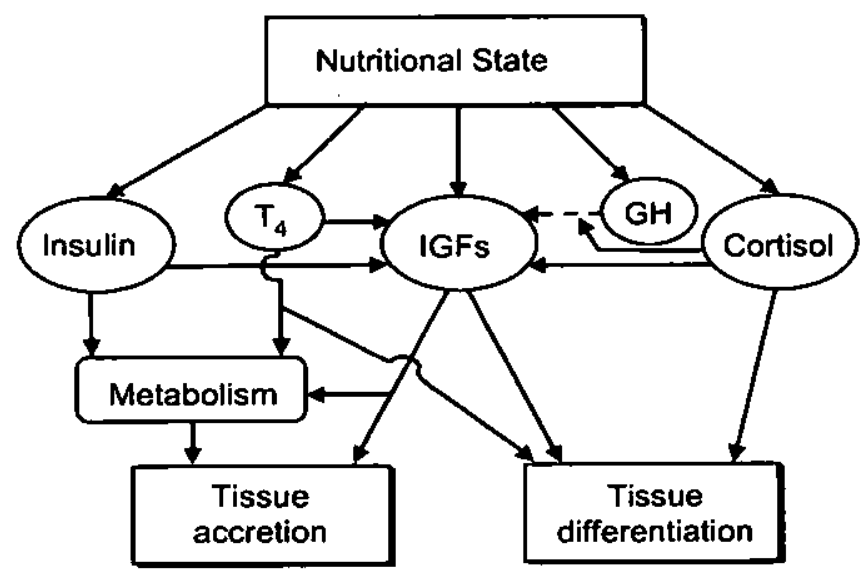

Fig. 6 Diagram illustrating the relationships between nutritional state, hormone concentrations, metabolism and tissue accretion and differentiation in the fetus. (from Fowden \& Forhead, 2004 with permission)

for many years. On the positive side, the phenotypic data collected from existing commercial dam-lines, as shown in Fig. 1, shows the potential to control the gene $x$ environment interaction and produce good sized litters that have a birth weight in the 1.5 to $2.0 \mathrm{~kg}$ range.

In terms of boar selection for placement in artificial insemination studs, similar effects of birth litter may have an important influence on lifetime sperm production. As in other organ systems, brain sparing effects in low birth weight male littermates should limit their testis development. Preliminary data supporting this suggestion is presented in Table 5 (FCRL Almeida, personal communication). In that particular study, new-born male littermates born to parity 4 to 6 sows, and in litters of 10 to 15 total pig born, were identified as falling into high (HW: range 1,800 to $2,200 \mathrm{~g}$ ) and low (LW: range 800 to $1,200 \mathrm{~g}$ ) birth weight groups relative to the average birth weight of their litter. A subset of 20 boars from each birth weight group was necropsied at birth and evidence of IUGR was confirmed by establishing that all brain:organ weight ratios were negatively impacted in LW versus $\mathrm{HW}$ offspring. Differences in testicular weight were associated with differences in the number of gonocytes and Sertoli cells per testicular cord.

Table 5. Mean birth weight, weight at castration (day 7), and gonadal data for male pigs born in litters of 10 to 15 and classified as high and low birth weight (bw) relative to the average birth weight of their litters. (FCRL. Almeida, personal communication)

\begin{tabular}{lcccc}
\hline Parameter & Low bw & High bw & SEM & P \\
\hline Birth weight $(\mathrm{kg})$ & 1.17 & 2.02 & 0.014 & $<0.05$ \\
Weight at day $7^{\prime}(\mathrm{kg})$ & 2.03 & 3.30 & 0.029 & $<0.05$ \\
Right testis weight $(\mathrm{g})$ & 0.42 & 0.95 & 0.012 & $<0.05$ \\
Left testis weight $(\mathrm{g})$ & 0.46 & 0.98 & 0.018 & $<0.05$ \\
Mean testicular weight, (g) & 0.44 & 0.97 & 0.014 & $<0.05$ \\
Right epididimal weight (g) & 0.20 & 0.31 & 0.009 & $<0.05$ \\
Left epididimal weight (g) & 0.20 & 0.27 & 0.007 & $<0.05$ \\
Gonocytes / testicular cord & 0.87 & 1.58 & 0.090 & $<0.05$ \\
Sertoli cells/ testicular cord & 19.22 & 22.36 & 0.419 & $<0.05$ \\
\hline
\end{tabular}


This above mentioned study provides some of the first evidence for significant impacts of birth weight on the population of spermatogonial stem cells (gonocytes) in the neonatal testis. Assuming that these results will be confirmed at the multiplication level in sire-line selection programs, the implications of birth weight for lifetime sperm production seem real. This suggests that prenatal programming of testis development will already predetermine the reported relationship between adult testis size and lifetime semen production.

\section{Demands on experimental designs and genomic-epigenomic analyses}

The review of Distl (2007) considered future trends in genomic selection that might address: (1) the current trends for hyperprolificacy to be invariably associated with low birth weight, and (2) the implications of overcrowding in the uterus in early gestation for later fetal and postnatal development. One of the conclusions in this paper was that: "Understanding of this "polygenic paradox" requires expanding the study design from studying single genes or proteins to use whole genome or protein approaches and to evaluate their multiple epistatic effects".

As we start to apply such multi-faceted analyses to understand the link between component traits for litter quality (ovulation rate, embryonic and fetal survival, several component traits for uterine capacity) and the genomic and epigenomic control of these phenotypic traits, the complexity of the experimental approach needed becomes equally complex. This seems to be a particularly difficult problem when deciding which tissues and from which litters, and even from which gender of littermate within litters, to submit to microarray analysis. For example, if the question relates to gene regulation in the placenta or embryo in utero in response to nutrient manipulations, the confounding combination of "noise" due to variable ovulation rate, embryo survival, uterine capacity, relative embryonic and placental development, and genderspecific effects needs to be accounted for in meaningful interpretation of microarray data. Our initial conclusion is that the complexity and elegance of the experimental designs needed to meet these challenges will a key element in the success applying "omic"- level analyses to the complex problems of prenatal programming.

\section{References}

Adams PH 1971 Intra-uterine growth retardation in the pig. II. Development of the skeleton. Biology of the Neonate $19341-353$.

Almeida FR, Kirkwood RN, Aherne FX \& Foxcroft GR 2000 Consequences of different patterns of feed intake during the estrous cycle in gilts on subsequent fertility. Journal of Animal Science 78 1556-1563.

Barker DJP 1994 Mothers, Babies and Diseases in Later Life, London: London BMJ Publishing.

Boulot S, Quesnel H \& Quiniou N 2008 Management of High Prolificacy in French Herds: Can We Alleviate Side Effects on Piglet Survival? Advances in Pork Production 19 1-18.

Burdge GC, Hanson MA, Slater-Jefferies JL \& Lillycrop KA 2007 Epigenetic regulation of transcription: a mechanism for inducing variations in phenotype (foetal programming) by differences in nutrition during early life? British Journal of Nutrition 97 1036-1046.

Clowes EJ, Aherne FX, Foxcroft GR \& Baracos VE 2003 Selective protein loss in lactating sows is associated with reduced litter growth and ovarian function.
Journal of Animal Science 81 753-764.

Distl O 2007 Mechanisms of regulation of litter size in pigs on the genome level. Reproduction in Domestic Animals 42 Supplement 2 10-16.

Finch AM, Antipatis C, Pickard AR \& Ashworth CJ 2002 Patterns of fetal growth within Large White $x$ Landrace and Chinese Meishan gilt litters at three stages of gestation. Reproduction Fertility \& Development 14 419-425.

Flecknell PA, Wootton R, John M \& Royston JP 1981 Pathological features of intra-uterine growth retardation in the piglet: differential effects on organ weights. Diagnostic Histopathology 4 295-298.

Fowden AL \& Forhead Al 2004 Endocrine mechanisms of intrauterine programming. Reproduction 127 515-526.

Foxcroft GR 1997 Mechanisms mediating nutritional effects on embryonic survival in pigs. Journal of Reproduction and Fertility Supplement 52 47-61.

Foxcroft GR, Dixon WT, Treacey BK, Jiang L, Novak S, Mao J \& Almeida FRCL 2000 Insights into conceptus- 
reproductive Iract interactions in the pig. Proceedings of the American Society of Animal Science 37 1-15.

Foxcroft GR \& Town S 2004 Prenatal programming of postnatal performance - the unseen cause of variance. Advances in Pork Production 15 269-279.

Foxcroft GR, Dixon WT, Novak S, Putman CT, Town SC \& Vinsky MD 2006 The biological basis for prenatal programming of postnatal performance in pigs. Journal of Animal Science 84 Suppl E105-112.

Foxcroft G, Bee G, Dixon W, Hahn $M$, Harding J, Patterson J, Putman T, Sarmento S, Smit M, Tse W-Y \& Town S 2007a Consequences of selection for litter size on piglet development. In Paradigms of Pig Science, pp 207-229, Eds J Wiseman, MA Varley, S McOrist \& B Kemp. Nottingham University Press, Nottingham, UK.

Foxcroft GR, Vinsky MD, Paradis F, Tse WY, Town SC, Putman CT, Dyck MK \& Dixon WT 2007b Macroenvironment effects on oocytes and embryos in swine. Theriogenology 68 Supplement 1 S30-39.

Gabler NK, Spencer JD, Webel DM \& Spurlock ME 2007 In utero and postnatal exposure to long chain (n-3) PUFA enhances intestinal glucose absorption and energy stores in weanling pigs. Journal of Nutrition 137 2351-2358.

Gondret F, Lefaucheur L, Louveau L, Lebret B, Pichodo $X$ \& Le Cozler Y 2005 Influence of piglet birth weight on postnatal growth performance, tissue lipogenic capacity and muscle histological traits at market weight. Livestock Production Science 93 137-146.

Harding JC, Auckland C, Patterson J \& Foxcroft GR 2006a Hidden ramifications of attaining 30 pigs per sow per year induced by adverse foetal programming. Proceedings of the $37 \mathrm{th}$ Annual Conference of the American Association of Swine Veterinarians; Pre Conference Symposium on "Sow Productivity and Reproduction" pp 1-6. Kansas City, Missouri, USA, March 4-7, 2006.

Harding JC, Auckland C, Patterson J \& Foxcroft GR $2006 \mathrm{~b}$ Prenatal programming of post-natal health and survival. Proceedings of Leman Reproductive Workshop: Achieving and exceeding sow production targets. College of Veterinary Medicine, University of Minnesota, pp 73-82, St. Paul, Minnesota, USA, September 23-26, 2006.

Hegarty PV \& Allen CE 1978 Effect of pre-natal runting on the post-natal development of skeletal muscles in swine and rats. Journal of Animal Science 46 1634-1640.

Hunter MG \& Paradis F 2009 Intra-Follicular Regulatory Mechanisms in the Porcine Ovary. In Control of Pig Reproduction VIII, pp 149-164. Eds H RodriguezMartinez, JL. Vallet and AJ Ziecik, Nottingham University Press, Nottingham.

IFIP 2007 National and regional results for French pig farms in 2006, pp. 41. (http:/www.ifip.asso.fr/service/ chail.htm)

Johnson RK, Nielsen MK \& Casey DS 1999 Responses in ovulation rate, embryonal survival, and litter traits in swine to 14 generations of selection to increase litter size. Journal of Animal Science 77 541-557.
Kelly TL \& Trasler JM 2004 Reproductive epigenetics. Clinical Cenetics 65 247-260.

Lucifero D, Mertineit C, Clarke HJ, Bestor TH \& Trasler JM 2002 Methylation dynamics of imprinted genes in mouse germ cells. Cenomics 79 530-538.

Mateo RD, Wu G, Bazer FW, Park JC, Shinzato I \& Kim SW 2007 Dietary L-arginine supplementation enhances the reproductive performance of gilts. Journal of Nutrition 137 652-656.

Paradis F, Novak S, Murdoch G, Dyck MK, Dixon WT \& Foxcroft GR 2009 Temporal regulation of BMP2, BMP6, BMP15, GDF-9, BMPR1A, BMPR1B, BMPR2 and TGF (beta\}R1 mRNA expression in the oocyte, granulosa and theca cells of developing preovulatory follicles in the pig. Reproduction (In press)

Park CH, Kim HS, Lee SG \& Lee CK 2009 Methylation status of differentially methylated regions at $\lg 2 /$ $\mathrm{H} 19$ locus in porcine gametes and preimplantation embryos. Genomics 93 179-186.

Patterson J, Wellen A, Hahn M, Pasternak A, Lowe J, DeHaas S, Kraus D, Williams N \& Foxcroft G 2008 Responses to delayed estrus after weaning in sows using oral progestagen treatment. Journal of Animal Science 86 1996-2004.

Quiniou N, Dagorn / \& Gaudre D 2002 Variation of piglets birth weight and consequences on subsequent performance. Livestock Production Science 78 63-70.

Quiniou N, Brossard L \& Quesnel H 2007 Impact of some sow's characteristics on birth weight variability. Proceedings $58^{\text {th }}$ Annual Meeting of the European Association for Animal Production, session 9, $n^{\circ} 5$, Dublin, Ireland, Aug 26-29, 2007.

Quinton VM, Wilton JW, Robinson JA \& Mathur PK 2006 Economic weights for sow productivity traits in nucleus pig populations. Livestock Science 99 69-77.

Rehfeldt C \& Kuhn G 2006 Consequences of birth weight for postnatal growth performance and carcass quality in pigs as related to myogenesis. Journal of Animal 84 Suppl E113-123.

Reik W 2007 Stability and flexibility of epigenetic gene regulation in mammalian development. Nature 447 425-432.

Rosendo A, Druet T, Gogue I \& Bidanel JP 2007 Direct responses to six generations of selection for ovulation rate or prenatal survival in Large White pigs. Journal of Animal Science 85 356-364.

Sinclair KD, Allegrucci C, Singh R, Gardner DS, Sebastian S, Bispham J, Thurston A, Huntley JF, Rees WD, Maloney CA, Lea RG, Craigon J, McEvoy TG \& Young LE 2007 DNA methylation, insulin resistance, and blood pressure in offspring determined by maternal periconceptional B vitamin and methionine status. Proceedings of the National Academy of Sciences USA 104 19351-19356.

Smit M 2007 Cenetic background of prenatal programming in pigs. MSc Minor Thesis, University of Wageningen, The Netherlands.

Town S 2004 Patterns of prenatal loss: Implications for placental and foetal development. Ph.D. Thesis, University of Alberta, Canada. 
Town SC, Putman CT, Turchinsky NI, Dixon WT \& Foxcroft GR 2004 Number of conceptuses in utero-affects porcine-fetal-muscle development. Reproduction 128 443-454.

Town SC, Patterson JL, Pereira CZ, Gourley C \& Foxcroft GR 2005 Embryonic and fetal development in a commercial dam-line genotype. Animal Reproduction Science 85 301-316.

Tse WY, Town SC, Murdoch GK, Novak S, Dyck MK, Putman CT, Foxcroft GR \& Dixon WT 2008 Uterine crowding in the sow affects litter sex ratio, placental development and embryonic myogenin expression in early gestation. Reproduction Fertility \& Development 20 497-504.

Vallet JL, Miles JR \& Freking BA 2009 Development of the pig placenta. In Control of Pig Reproduction VIII, pp 265-279. Eds H Rodriguez-Martinez, JL Vallet and AJ Ziecik, Nottingham University Press, Nottingham.

van der Lende T, Hazeleger W \& de Jager D 1990 Weight distribution within litters at the early foetal stage and at birth in relation to embryonic mortality in the pig. Livestock Production Science 26 53-65.

van der Lende T \& de Jager D 1991 Death risk and preweaning growth rate of piglets in relation to the within-litter weight distribution at birth. Livestock Production Science 28 73-84.

Vinsky MD, Novak S, Dixon WT, Dyck MK \& Foxcroft GR 2006 Nutritional restriction in lactating primiparous sows selectively affects female embryo survival and overall litter development. Reproduction Fertility \& Development 18 347-355.

Vinsky MD, Paradis F, Dixon WT, Dyck MK \& Foxcroft GR 2007a Ontogeny of metabolic effects on embryonic development in lactating and weaned primiparous sows. Reproduction Fertility \& Development 19 603-611.

Vinsky MD, Murdoch GK, Dixon WT, Dyck MK \& Foxcroft GR 2007b Altered epigenetic variance in surviving litters from nutritionally restricted lactating primiparous sows. Reproduction Fertility \& Development 19 430-435.

Vonnahme KA, Wilson ME, Foxcroft GR \& Ford SP 2002 Impacts on conceptus survival in a commercial swine herd. Journal of Animal Science 80 553-559.

Widdowson EM 1971 Intra-uterine growth retardation in the pig. I. Organ size and cellular development at birth and after growth to maturity. Biology of the Neonate 19 329-340.

Wootton R, Flecknell PA, Royston JP \& John M 1983 Intrauterine growth retardation detected in several species by non-normal birthweight distributions. Journal of Reproduction and Fertility 69 659-663.

Wu G, Bazer FW, Wallace IM \& Spencer TE 2006 Board-invited review: intrauterine growth retardation: implications for the animal sciences. Journal of Animal Science 84 2316-2337.

Yang H, Foxcroft GR, Pettigrew JE, Johnston LJ, Shurson GC, Costa AN \& Zak LJ 2000 Impact of dietary lysine intake during lactation on follicular development and oocyte maturation after weaning in primiparous sows. Journal of Animal Science 78 993-1000.

Zak LJ, Cosgrove JR, Aherne FX \& Foxcroft GR 1997 Pattern of feed intake and associated metabolic and endocrine changes differentially affect postweaning fertility in primiparous lactating sows. Journal of Animal Science 75 208-216. 